\title{
Influence of cement substitution by calcareous fly ash on the mechanical properties of polymer-cement composites
}

\author{
Beata Jaworska ${ }^{1, *}$, Paweł Łukowski ${ }^{1}$, and Jerzy Jaworski ${ }^{1}$ \\ ${ }^{1}$ Warsaw University of Technology, Faculty of Civil Engineering, A1. Armii Ludowej 16, \\ 00-637 Warsaw, Poland
}

\begin{abstract}
The aim of the presented research was to determine the influence of cement substitution with calcareous fly ash on the mechanical properties of polymer-cement composites. Coal combustion products such as calcareous fly ash have been already used in traditional cement composites as a part of cement and considered potential additions for concrete but its introduction into polymer-cement composites is still under preliminary investigation. The morphology of fly ash causes problems with its compatibility with polymer-cement binders but its insertion into those building materials is another way to utilize mineral combustion products that are cumbersome in storage and recycling. The influence of the mineral addition on polymer-cement composites containing $20 \%$ of polymer was especially taken into consideration. Mechanical properties of polymercement mortars modified with calcareous fly ash were tested after 28 and 90 days of curing. As a part of preliminary study, activity index of mineral addition was determined. Polymer-cement composites containing calcareous fly ash were characterized by higher flexural and tensile strength comparing to standardized mortar, even for the mortars containing $40 \%$ of mineral addition. The negative effect of the polymer-cement composites modification with calcareous fly ash was especially observed on the compressive strength of this composites.
\end{abstract}

\section{Introduction}

Polymer-cement concretes and mortars are part of the concrete-like composites group in which a polymer modifier is present in addition to the cement binder. The polymer-cement composites production technology is similar to the technology of obtaining conventional cement concrete. The content of the polymer modifier is usually in the range of $10 \div 20 \%$ by cement mass, but only a small number of polymers are suitable for the modification of cement binder. The presence of a polymer modifier causes the increase of flexural and tensile strength of the composite and the reduction of its permeability [1]. Chemical resistance and freezing/thawing resistance, and - therefore - durability of the material are improved.

\footnotetext{
${ }^{*}$ Corresponding author: b.jaworska@il.pw.edu.pl
} 
Polymer-cement composites are used is such areas as repairs and protection of concrete structure [2], production of industrial floors and pavements [3] as well as production of precast elements [4].

The main obstacle to using polymer-cement composites is their high material cost, although lower than the cement less resin composites, due to the smaller amount of the polymer needed to produce them. The need to reduce the material cost while maintaining the material properties leads to a search for new material solutions [1]. One of the methods to reduce the material cost is the replacement of some components with cheaper substitutes, both natural resources and waste materials. Examples of such materials are fly ashes - coal combustion products (CCP).

Whereas siliceous fly ash is commonly used as addition to concretes according to PN-EN 206 [5] and common cement according to PN-EN 197-1 [6], the calcareous fly ash is not such an obvious choice. This lignite combustion product differs from siliceous ashes both in chemical composition and in properties [7, 8]. Most of all, its irregular grains with a porous surface [9] are the reason for the increased water demand of composites containing this ash, thus negatively affecting the workability of the concrete mix, and consequently the properties of the hardened material.

The utilization of mineral wastes, also including coal combustion products, is a part of a sustainable development strategy, according to which, inter alia, it is necessary to minimize the consumption of matter, re-use elements and materials and effectively manage waste.

The purpose of this work was to solve the scientific problem regarding the influence of the presence of coal combustion product - calcareous fly ash - on the mechanical properties of polymer-cement composites.

\section{Experimental}

\subsection{Methodology of the research program}

The aim of the presented research was to determine the influence of cement substitution by calcareous fly ash on the mechanical properties of polymer-cement composites. Mixtures were designed with the following assumptions:

- dosage levels of calcareous fly ash: $0 \div 40 \%$ of cement mass,

- constant polymer content: $20 \%$ of cement mass,

- constant level of water-cement ratio equal to 0.5.

Polymer-cement mortars were prepared using Portland cement CEM I 42.5R, standard sand fulfilling requirements of PN-EN 196-1 [10], a water dispersion of styrene-acrylic copolymer and calcareous fly ash from one of the Polish power plants. The reference material used in this research was standardized cement mortar according to PN-EN 196-1.

\subsection{Testing procedure}

Mechanical properties of polymer-cement composites were tested after 28 and 90 days of curing in mixed wet conditions. For the first day of curing specimens were covered with polyethylene sheets and, after demoulding, immersed for five days in water at $20-22^{\circ} \mathrm{C}$. These are favourable conditions for the hydration of cement binder. After removing specimens from water, until testing, they were held in air-dry conditions at temperature of $20-22^{\circ} \mathrm{C}$ and relative humidity of $60 \pm 5^{\circ} \mathrm{C}$. The air-dry condition is adequate for the formation of a continuous polymer film. Standardized mortars were stored in wet 
conditions as recommended in PN-EN 196-1. As a part of preliminary study, the activity index of calcareous fly ash was tested.

\subsection{Activity index of mineral addition}

The activity index of calcareous fly ash which was used in the research as a substitution of cement in polymer-cement composites was tested according to PN-EN 450-1 [11] and is presented in Table 1, Figure 1.

Table 1. Compressive strength $\left(f_{c}\right)$ and activity index (AI) of specimens after 28 and 90 days of curing (CFA - calcareous fly ash, SM - standardized mortar - reference level).

\begin{tabular}{|c|c|c|c|c|c|}
\hline No. & Specimen & $\mathbf{f}_{\mathbf{c} 28}, \mathbf{M P a}$ & $\mathbf{A I}_{\mathbf{2 8}}, \boldsymbol{\%}$ & $\mathbf{f}_{\mathbf{c 9 0}}, \mathbf{M P a}$ & $\mathbf{A I}_{\mathbf{9 0}}, \boldsymbol{\%}$ \\
\hline 1 & CFA & 41.4 & $\mathbf{8 3 . 0}$ & 49.5 & $\mathbf{8 5 . 9}$ \\
\hline 2 & SM & 49.9 & - & 57.6 & - \\
\hline
\end{tabular}

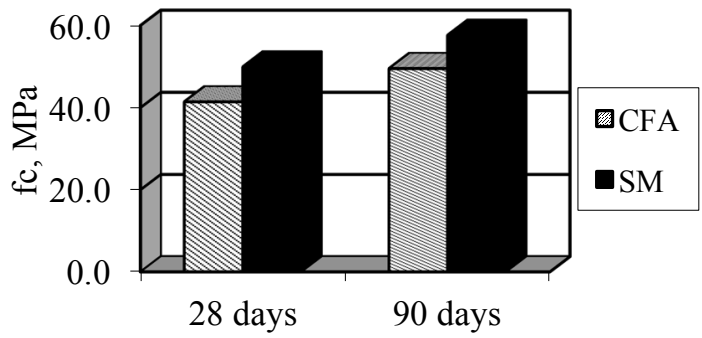

Fig. 1. Compressive strength of specimens after 28 and 90 days of curing (CFA - calcareous fly ash, SM - standardized mortar - reference level).

Calcareous fly ash was characterized by high activity index, reaching a value above $75 \%$ after 28 days and above $85 \%$ after 90 days of curing the specimens.

\subsection{Mechanical properties of polymer-cement composites containing calcareous fly ash}

Mechanical properties of polymer-cement composites containing calcareous fly ash were tested after 28 and 90 days of curing. The investigation was carried out for composites modified with $20 \%$ content of polymer and up to $40 \%$ content of mineral addition (by cement mass). Mechanical properties of these composites were tested in accordance with PN-85/B-04500 [12].

\subsubsection{Flexural strength}

Cement mortars containing $40.0 \%$ of mineral addition were characterized by the smallest flexural strength - 7.5 MPa after 28 days of curing and 8.3 MPa after 90 days of curing (Table 2). The cement substitution by calcareous fly ash in polymer-cement composites did not result in larger differences in the obtained flexural strength results. Polymer-cement composites containing calcareous fly ash were characterized by flexural strength of up to 12.0 MPa. Polymer-cement composites containing $40 \%$ of mineral addition were characterized by the smallest flexural strength $(9.8$ and $10.5 \mathrm{MPa}$ after 28 and 90 days of curing respectively). Cement mortars containing $40 \%$ of calcareous fly ash were characterized by $1.3 \%$ and $4.6 \%$ decrease of flexural strength and polymer-cement 
composites with $40 \%$ of calcareous fly ash were characterized by $17.6 \%$ and $14.6 \%$ decrease of flexural strength, after 28 and 90 days of curing respectively, comparing to the mortars without fly ash (Table 2, Figure 2).

Table 2. Flexural strength of PCC mortars with different content of calcareous fly ash - after different time of curing ( $\mathrm{p} / \mathrm{c}$ - polymer content by cement mass, $\mathrm{m} / \mathrm{c}$ - mineral addition by cement mass, $\mathrm{SD}$ - standard deviation, $\mathrm{CV}$ - variability index)

\begin{tabular}{|c|c|c|c|c|c|c|c|c|}
\hline \multirow{2}{*}{ No. } & \multirow{2}{*}{$\mathbf{p} / \mathbf{c}, \boldsymbol{*}$} & \multicolumn{6}{|c|}{ m/c, \% } & \multicolumn{3}{|c|}{ 28 days } & \multicolumn{3}{c|}{ 90 days } \\
\cline { 4 - 10 } & & & Average value & SD & CV, \% & Average value & SD & CV, \% \\
\hline 1 & 0.0 & 0.0 & 7.6 & 0.3 & 3.8 & 8.7 & 0.4 & 4.6 \\
\hline 2 & 0.0 & 5.0 & 8.6 & 0.8 & 8.7 & 9.2 & 0.2 & 2.7 \\
\hline 3 & 0.0 & 10.0 & 8.1 & 0.8 & 9.9 & 8.6 & 0.2 & 2.9 \\
\hline 4 & 0.0 & 15.0 & 7.7 & 06 & 8.2 & 8.4 & 0.2 & 2.9 \\
\hline 5 & 0.0 & 20.0 & 8.0 & 0.1 & 0.8 & 8.8 & 0.3 & 3.7 \\
\hline 6 & 0.0 & 25.0 & 7.6 & 0.4 & 5.6 & 8.5 & 0.2 & 2.8 \\
\hline 7 & 0.0 & 30.0 & 7.5 & 0.4 & 5.6 & 8.5 & 0.0 & 0.0 \\
\hline 8 & 0.0 & 40.0 & 7.5 & 0.5 & 6.2 & 8.3 & 0.4 & 4.2 \\
\hline 9 & 20.0 & 0.0 & 11.9 & 0.1 & 0.7 & 12.3 & 0.9 & 7.4 \\
\hline 10 & 20.0 & 5.0 & 10.6 & 0.1 & 1.1 & 12.1 & 0.1 & 0.9 \\
\hline 11 & 20.0 & 10.0 & 10.4 & 0.3 & 3.1 & 12.2 & 0.0 & 0.0 \\
\hline 12 & 20.0 & 15.0 & 9.6 & 0.1 & 1.3 & 11.9 & 0.3 & 2.5 \\
\hline 13 & 20.0 & 20.0 & 9.8 & 0.3 & 3.2 & 11.4 & 0.3 & 2.9 \\
\hline 14 & 20.0 & 25.0 & 9.8 & 0.1 & 0.9 & 11.4 & 0.4 & 3.2 \\
\hline 15 & 20.0 & 30.0 & 9.9 & 0.2 & 1.6 & 10.9 & 0.1 & 1.1 \\
\hline 16 & 20.0 & 40.0 & 9.8 & 0.0 & 0.0 & 10.5 & 0.1 & 0.6 \\
\hline
\end{tabular}
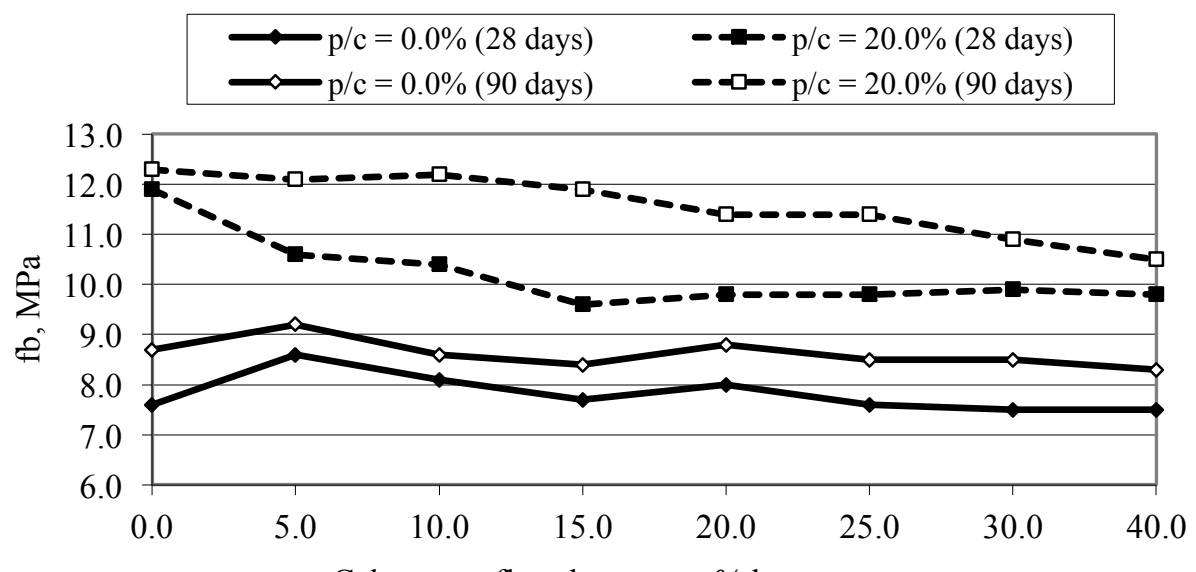

Calcareous fly ash content, \% by cement mass

Fig. 2. Flexural strength of polymer-cement composites containing different content of calcareous fly ash after different time of curing. 


\subsubsection{Tensile strength}

Cement mortars containing $40.0 \%$ of mineral addition were characterized by the smallest tensile strength $(3.1 \mathrm{MPa})$. The cement substitution by calcareous fly ash in polymer-cement composites did not result in larger differences in the obtained tensile strength results. Polymer-cement composites containing calcareous fly ash were characterized by tensile strength of up to $6.0 \mathrm{MPa}$. Polymer-cement composites modified with $40 \%$ of calcareous fly ash were characterized by $11.1 \%$ and $15.8 \%$ decrease of tensile strength, after 28 and 90 days of curing respectively (Table 3, Figure 3).

Table 3. Tensile strength of PCC mortars with different content of calcareous fly ash - after different time of curing ( $\mathrm{p} / \mathrm{c}$ - polymer content by cement mass, $\mathrm{m} / \mathrm{c}$ - mineral addition by cement mass, SD standard deviation, CV - variability index).

\begin{tabular}{|c|c|c|c|c|c|c|c|c|}
\hline \multirow{3}{*}{ No. } & \multirow{3}{*}{$\mathrm{p} / \mathrm{c}, \%$} & \multirow{3}{*}{$\mathbf{m} / \mathbf{c}, \%$} & \multicolumn{6}{|c|}{ Tensile strength, MPa } \\
\hline & & & \multicolumn{3}{|c|}{28 days } & \multicolumn{3}{|c|}{90 days } \\
\hline & & & Average value & SD & $\mathrm{CV}, \%$ & Average value & SD & $\mathrm{CV}, \%$ \\
\hline 1 & 0.0 & 0.0 & 3.1 & 0.3 & 8.0 & 3.2 & 0.2 & 6.3 \\
\hline 2 & 0.0 & 5.0 & 4.2 & 0.2 & 4.8 & 4.6 & 0.3 & 6.5 \\
\hline 3 & 0.0 & 10.0 & 4.1 & 0.1 & 2.4 & 4.9 & 0.2 & 3.1 \\
\hline 4 & 0.0 & 15.0 & 3.9 & 0.3 & 8.1 & 4.6 & 0.1 & 1.5 \\
\hline 5 & 0.0 & 20.0 & 3.6 & 0.0 & 0.0 & 4.4 & 0.1 & 1.3 \\
\hline 6 & 0.0 & 25.0 & 3.5 & 0.1 & 2.4 & 4.3 & 0.0 & 0.0 \\
\hline 7 & 0.0 & 30.0 & 3.5 & 0.3 & 8.6 & 4.0 & 0.1 & 2.5 \\
\hline 8 & 0.0 & 40.0 & 3.1 & 0.1 & 1.9 & 4.1 & 0.1 & 2.4 \\
\hline 9 & 20.0 & 0.0 & 5.4 & 0.3 & 4.6 & 5.7 & 0.2 & 3.5 \\
\hline 10 & 20.0 & 5.0 & 5.6 & 0.4 & 7.1 & 6.1 & 0.0 & 0.0 \\
\hline 11 & 20.0 & 10.0 & 5.1 & 0.1 & 1.1 & 5.9 & 0.1 & 1.7 \\
\hline 12 & 20.0 & 15.0 & 5.1 & 0.0 & 0.0 & 5.6 & 0.1 & 1.1 \\
\hline 13 & 20.0 & 20.0 & 5.2 & 0.2 & 3.8 & 5.4 & 0.1 & 1.9 \\
\hline 14 & 20.0 & 25.0 & 5.2 & 0.1 & 3.3 & 5.2 & 0.1 & 1.0 \\
\hline 15 & 20.0 & 30.0 & 5.4 & 0.2 & 3.7 & 5.1 & 0.1 & 2.0 \\
\hline 16 & 20.0 & 40.0 & 4.8 & 0.1 & 1.2 & 4.8 & 0.1 & 1.2 \\
\hline
\end{tabular}

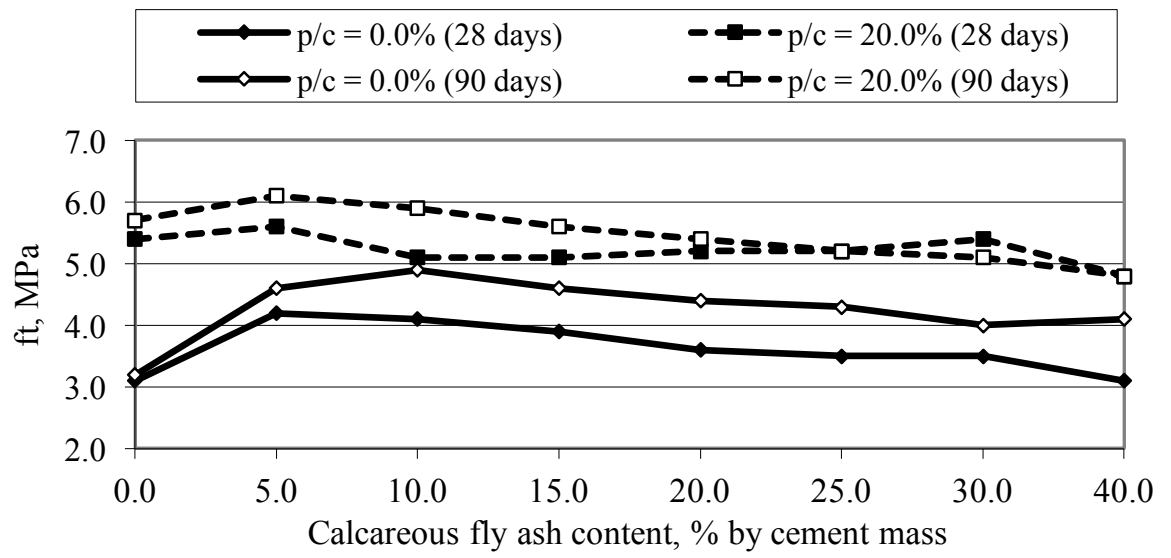

Fig. 3. Tensile strength of polymer-cement composites containing different content of calcareous fly ash after different time of curing. 


\subsubsection{Compressive strength}

Polymer-cement composites containing calcareous fly ash were characterized by compressive strength of up to $46.0 \mathrm{MPa}$. Polymer-cement composites containing $40.0 \%$ of mineral addition were characterized by the smallest compressive strength (30.4 MPa) even comparing to cement mortar modified with the same amount of fly ash. Polymer-cement composites modified with $40 \%$ of calcareous fly ash were characterized by $29.0 \%$ and $25.7 \%$ decrease of compressive strength, after 28 and 90 days of curing respectively (Table 4, Figure 4).

Table 4. Compressive strength of PCC mortars with different content of calcareous fly ash - after different time of curing ( $\mathrm{p} / \mathrm{c}$ - polymer content by cement mass, $\mathrm{m} / \mathrm{c}-$ mineral addition by cement mass, $\mathrm{SD}$ - standard deviation, $\mathrm{CV}$ - variability index).

\begin{tabular}{|c|c|c|c|c|c|c|c|c|}
\hline \multirow{3}{*}{ No. } & \multirow{3}{*}{$\mathrm{p} / \mathrm{c}, \%$} & \multirow{3}{*}{$\mathbf{m} / \mathbf{c}, \%$} & \multicolumn{6}{|c|}{ Compressive strength, MPa } \\
\hline & & & \multicolumn{3}{|c|}{28 days } & \multicolumn{3}{|c|}{90 days } \\
\hline & & & Average value & SD & $\mathrm{CV}, \%$ & Average value & SD & $\mathrm{CV}, \%$ \\
\hline 1 & 0.0 & 0.0 & 48.3 & 1.4 & 2.9 & 59.6 & 1.4 & 2.4 \\
\hline 2 & 0.0 & 5.0 & 50.6 & 0.7 & 1.4 & 59.2 & 1.8 & 3.1 \\
\hline 3 & 0.0 & 10.0 & 46.7 & 0.3 & 0.7 & 55.1 & 1.1 & 2.0 \\
\hline 4 & 0.0 & 15.0 & 42.3 & 1.0 & 2.4 & 53.6 & 1.3 & 2.3 \\
\hline 5 & 0.0 & 20.0 & 41.7 & 1.3 & 3.1 & 52.2 & 0.7 & 1.4 \\
\hline 6 & 0.0 & 25.0 & 38.7 & 1.6 & 4.0 & 49.7 & 1.8 & 3.5 \\
\hline 7 & 0.0 & 30.0 & 35.2 & 0.6 & 1.7 & 48.1 & 2.4 & 5.0 \\
\hline 8 & 0.0 & 40.0 & 31.7 & 1.4 & 4.3 & 40.2 & 0.7 & 1.6 \\
\hline 9 & 20.0 & 0.0 & 42.8 & 0.4 & 1.0 & 47.1 & 0.7 & 1.4 \\
\hline 10 & 20.0 & 5.0 & 39.5 & 1.4 & 3.6 & 46.2 & 0.8 & 1.7 \\
\hline 11 & 20.0 & 10.0 & 39.4 & 0.9 & 2.2 & 44.8 & 1.3 & 2.9 \\
\hline 12 & 20.0 & 15.0 & 37.6 & 1.4 & 3.8 & 43.4 & 0.8 & 1.8 \\
\hline 13 & 20.0 & 20.0 & 37.0 & 0.7 & 1.9 & 43.4 & 0.2 & 0.5 \\
\hline 14 & 20.0 & 25.0 & 35.1 & 0.6 & 1.6 & 40.2 & 0.9 & 2.3 \\
\hline 15 & 20.0 & 30.0 & 31.6 & 0.6 & 1.8 & 37.2 & 0.3 & 0.8 \\
\hline 16 & 20.0 & 40.0 & 30.4 & 0.4 & 1.2 & 35.0 & 0.5 & 1.5 \\
\hline
\end{tabular}




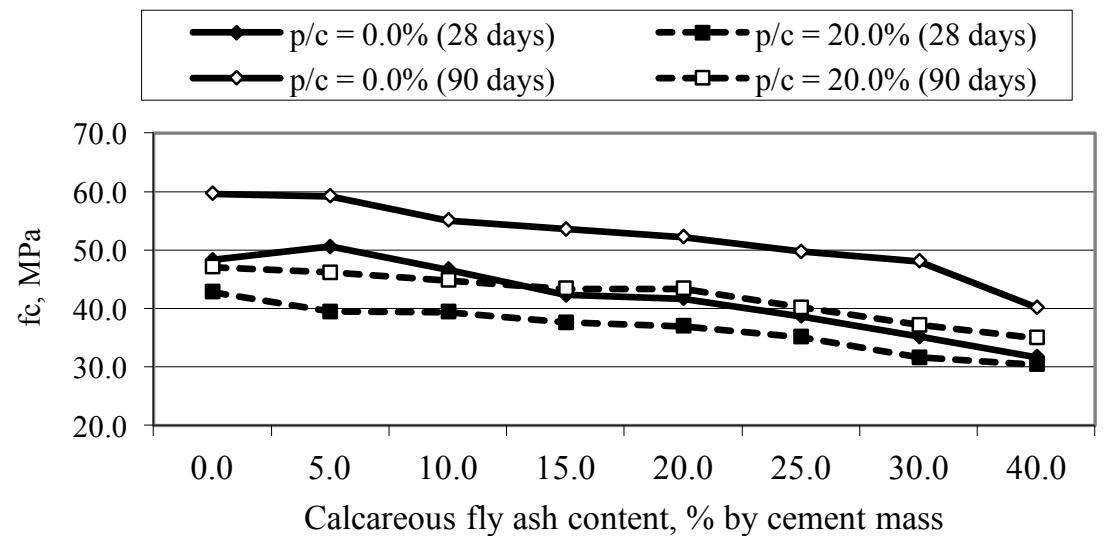

Fig. 4. Compressive strength of polymer-cement composites containing different content of calcareous fly ash after different time of curing.

\section{Conclusions}

Adding calcareous fly ash to the polymer-cement composites had more influence on the flexural strength of this composites than on the flexural strength of cement mortars. Polymer-cement composites containing $40 \%$ of mineral addition were characterized by almost $18 \%$ and $15 \%$ (after 28 and 90 days of curing respectively) lower flexural strength comparing to polymer-cement composites without ash. Despite this, their flexural strength was higher by about $20 \%$ than the flexural strength of standardized cement mortar.

Also, when taking into consideration the influence of cement substitution with calcareous fly ash on the tensile strength of these composites, it can be seen that the addition up to $40 \%$ of coal combustion product caused its reduction, but still all the polymer-cement composites were characterized by higher tensile strength comparing to cement mortars.

The biggest influence of calcareous fly ash content was observed for compressive strength. Polymer-cement composites modified with $40 \%$ of calcareous fly ash were characterized by $29.0 \%$ and $25.7 \%$ decrease of compressive strength. Despite this, the decrease was smaller than in the case of cement mortars, where substitution of cement with $40 \%$ of calcareous fly ash resulted in $34.4 \%$ and $32.6 \%$ decrease in compressive strength, after 28 and 90 days of curing respectively.

The studies presented in this paper showed that it is possible to use calcareous fly ash (even in large quantities, up to $40 \%$ of cement mass) in polymer-cement composites. The obtained composites were characterized by similar or slightly worse (decrease in strength $\leq 30 \%$ ) mechanical properties comparing to polymer-cement composites without fly ash.

\section{References}

1. D.W. Fowler, Cem.Con.Com. 21, 449-452 (1999)

2. F. Giustozzi, Con. Buil. Mat. 111, 502-512 (2016)

3. D. Jeongyun, S. Yangseob, Cem. Con. Res. 33, 1497-1505 (2003)

4. L. Czarnecki, P. Łukowski, Cem. Wap. Bet. 5, 243-258 (2010)

5. PN-EN 206+A1 (2016-12) 
6. PN-EN 197-1 (2012)

7. J. Małolepszy, MATBUD'2011, 17- 48 (2011)

8. B. Jaworska, J.J. Sokołowska, P. Łukowski, J. Jaworski, ACE, LXI, 4 (2015)

9. Z. Giergiczny, Role of high calcium and low calcium fly ashes in shaping properties of construction binders and cement materials (Kraków, 2006)

10. PN-EN 196-1 (2006)

11. PN-EN 450-1 (2012)

12. $\mathrm{PN}-85 / \mathrm{B}-04500$ (1985) 